\title{
Oropharyngeal Administration of Colostrum for Preventing Necrotizing Enterocolitis and Late-onset Sepsis in Preterm Infants with Gestational Age $\leq 32$ Weeks: A Single-center Randomized Controlled Trial
}

\section{xia ouyang}

Fujian Province Maternal and Child Health Hospital: Fujian Provincial Maternity and Children's Hospital https://orcid.org/0000-0002-8034-5732

\section{changyi yang}

Fujian Province Hospital for Women and Children: Fujian Provincial Maternity and Children's Hospital wenlong xiu ( $\nabla$ wlxiu1979@163.com )

Fujian Province Hospital for Women and Children: Fujian Provincial Maternity and Children's Hospital yanhua hu

Fujian Province Maternal and Child Health Hospital: Fujian Provincial Maternity and Children's Hospital susu mei

Fujian Province Maternal and Child Health Hospital: Fujian Provincial Maternity and Children's Hospital qin lin

Fujian Province Maternal and Child Health Hospital: Fujian Provincial Maternity and Children's Hospital

\section{Research}

Keywords: oropharyngeal administration of colostrum, infant, preterm, necrotizing enterocolitis, late-onset sepsis

Posted Date: January 15th, 2021

DOI: https://doi.org/10.21203/rs.3.rs-145820/v1

License: (c) (i) This work is licensed under a Creative Commons Attribution 4.0 International License. Read Full License

Version of Record: A version of this preprint was published at International Breastfeeding Journal on August 21st, 2021. See the published version at https://doi.org/10.1186/s13006-021-00408-x. 


\section{Abstract}

\section{Background}

Oropharyngeal administration of colostrum (OAC) may provide immunoprotective and anti-inflammatory effects that potentially reduce the incidence of necrotizing enterocolitis (NEC) and late-onset sepsis (LOS) and improve short-term outcomes.

Objective

To evaluate the role of OAC in the early prevention of NEC and LOS in preterm infants with gestational age $(G A) \leq 32$ weeks.

Methods

A randomized, placebo-controlled trial was conducted in a 40-bed tertiary neonatal intensive care unit (NICU) in China. Preterm infants with GA $\leq 32$ weeks were divided randomly into an OAC group, which received $0.4 \mathrm{ml}$ maternal colostrum smearing via the oropharyngeal route every 3 hours for 10 days beginning within the first 48 hours after birth, and a control group, which received normal saline instead. Data from the two groups were collected and compared.

Results

A total of 127 patients in the OAC group and 125 patients in the control group were finally enrolled. The incidence of NEC (Bell stage 2 or 3 ) and LOS was lower in the OAC group [2.4\% vs. $10.4 \%, \chi^{2}=6.845$, $\square=0.009 ; 4.7 \%$ vs. $\left.13.6 \%, \chi^{2}=5.983, \square=0.014\right]$. In addition, the incidence of intraventricular hemorrhage (IVH) (stage 3 or 4 ) was lower [ $1.6 \%$ vs. $\left.7.2 \%, \chi^{2}=4.775, \square=0.029\right]$, and the time of achieving full enteral feeding was shorter [ 22.0 days vs. 25.0 days $\square Z=6 \rrbracket 424.500 \otimes P=0.009$ )] in the OAC group. No cases of adverse reactions were observed in either group.

Conclusions

OAC is a safe and simple NICU procedure that yields a potential advantage in decreasing the incidence of NEC, LOS, and severe IVH and shortening the time to achieve full enteral feeding in preterm infants with $\mathrm{GA} \leq 32$ weeks.

Trial registration

Chinese Clinical Trial Registry, ChiCTR1900023697, Registered 8 June 2019, Retrospectively registered, http://www.chictr.org.cn/edit.aspx? pid = 39398

\section{Introduction}


Necrotizing enterocolitis (NEC) and late-onset sepsis (LOS) are the major risk factors for mortality and morbidity in premature infants ${ }^{[1]}$. The incidence of NEC is $2 \sim 7 \%$ among infants with gestational age(GA) $<32$ weeks and $5 \sim 22 \%$ among infants with birth weight $\triangle B W \|<1000$ grams; the rate of LOS is $21 \%$ among infants with GA $25 \sim 28$ weeks and $28 \%$ among infants with a BW of $751 \sim 1,000$ grams $^{[2]}$. There is plenty of evidence that supports a multiple-factorial mechanism for NEC and LOS. The mechanism requires the concurrent presence of an immature immune system (increased susceptibility), triggers that lead to dysbiosis (disruption of the normal intestinal bacterial microbiome, resulting in increased growth of potentially pathogenic bacteria), and an exaggerated inflammatory host response with release of cytokines and chemokines ${ }^{[3-6]}$.

Breast milk is considered the perfect nutrition and contains a diverse array of microbiota and myriad biologically active components, including hepatocyte growth factor (HGF), transforming growth factor- $\beta$ $(T G F-\beta)$, immunoglobulin $A(\operatorname{IgA})^{[7]}$, platelet activating factor (PAF), lactoferrin and oligosaccharides etc. [8]. Previous reports have shown immunoprotective, anti-inflammatory and intestinal maturity effects from a mother's colostrum when administered early to the oropharyngeal pouch ${ }^{[9,10]}$.

In the early days after birth, most preterm infants with $\mathrm{GA} \leq 32$ weeks must be fed through a nasogastric tube and thus cannot benefit from oral protection conferred by colostrum. Therefore, some scholars have proposed using oral immune therapy to regulate the immune function of preterm infants and improve outcomes. In 2009, Rodriguez first proposed the concept of "oropharyngeal administration of colostrum $(\mathrm{OAC})$ " for very low birth weight (VLBW) premature infants, and the author believed that OAC was a way to keep newborns exposed constantly to growth factors and protective biological factors in amniotic fluid within the early period after delivery ${ }^{[11]}$. However, theoretical debate and inconsistency of findings remain. Therefore, this investigation was aimed to determine whether OAC could safely reduce the incidence of LOS and NEC in preterm infants with $G A \leq 32$ weeks and improve their short-term prognosis.

\section{Methods And Materials}

\section{Study setting}

This study was a prospective, randomized, controlled, nonblind trial conducted among preterm infants who were admitted and cared for in a 40-bed tertiary neonatal intensive care unit (NICU) within 24 hours after birth on Jan 1, 2019 Sep 30, 2020. This study was reviewed by the Ethics Committee of Fujian Provincial Maternity and Children's Hospital (No: 2017 - 502) and was registered in the Chinese Clinical Trial Registry (Registration ID: ChiCTR1900023697).

\section{Patients and study design}

Inclusion criterion: $\mathrm{GA} \leq 32$ weeks. Exclusion criteria: (1) Mothers prohibited from breastfeeding because of conditions such as having active tuberculosis or AIDS, being diagnosed and treated by radioisotopes, being treated with special medications excreted in breast milk, herpes simplex virus infection and 
damage in the breasts; (2) Births complicated with severe gastrointestinal malformations or congenital chromosomal diseases; and (3) Admission to the hospital with rapid serum antibody testing for cytomegalovirus IgG and IgM by enzyme-linked immunosorbent assay and urine cytomegalovirus DNA testing, which indicated that the patient had congenital cytomegalovirus infection. Informed consent was obtained from the guardians before they participated in the study.

Baseline characteristics data: The data collected in the standardized Access Database included the following: (1) The demographics and baseline characteristics of the infants: gender, gestational age, birth weight, proportion of small for gestational age (SGA) infants, proportion of extremely low birth weight (ELBW) infants, proportion of sicker infants, head circumference at birth, 5 min Apgar score, transport risk index of physiologic stability (TRIPS) score (including body temperature, respiratory status, systolic blood pressure, response to stimulation), diagnosis with neonatal respiratory distress syndrome (NRDS), use of pulmonary surfactant (PS), percentage of infants who had established enteral feeding within 24 hours after birth, time to start OAC/normal saline (NS), breastfeeding rate, and breastfeeding days. (2) The demographics of their mothers included maternal age, pregnancy complications (diabetes, hypertension), premature rupture of membranes, confirmed chorioamnionitis by placental pathology, maternal medicine exposure (glucocorticoids, magnesium sulfate), number of fetuses and mode of delivery.

\section{Study groups and experimental design}

All research subjects were separated into an OAC group and a control group through a random number table at admission by the appointed person. Blinding was not possible because of the nature of the intervention. (1) In the OAC group, breastmilk was collected from both sides of the mother's breast by a hospital-grade electric milk pump within the first 24 hours after birth at a frequency of 10 min on each side every 3 hours (8 times per day). Breastmilk was stored in uniform-disposable-cleaning-sealed cups, which were marked with the patients' name, admission number (AD), collected time and volume.

Breastmilk was sent from the families to the ward by cold-chain for nurses' acceptance and registration into the Milk Bank Refrigerator, which needed to be done within 4 hours after breastmilk collection. The OAC could be started once the breastmilk was received. The primary nurse suctioned $0.4 \mathrm{ml}$ breastmilk into a $1 \mathrm{ml}$ syringe after the milk was warmed in a water bath and then dripped $0.2 \mathrm{ml}$ breastmilk into each side of the infant's oral cavity. With the help of a sterile silicone fingerstall, breastmilk was applied evenly on the cheeks, palate, lingual surface, gingiva and lips for no less than 2 min every 3 hours (8 times per day). This treatment was started within 48 hours after birth until the 10th day. (2) In the control group, the primary nurse used the same methods and frequencies as the OAC group, only replacing breastmilk with NS.

The respiratory rate, heart rate, and transcutaneous oxygen saturation of the infants were monitored during the procedure. The procedure was suspended when any of the following cases occurred: apnea, heart rate $<90$ or $>180$ beats/min, transcutaneous oxygen saturation $<88 \%$. The oral mucous membrane was observed after the procedure. 
ELBW or sicker infants were most at risk for NEC or LOS and might not have tolerated the OAC intervention. Therefore, subgroup analyses were conducted in ELBW and sicker infants who were defined as infants whose mechanical ventilation was started within the first 3 postnatal days and continued through at least 3 days or until death.

\section{Routine care}

Except for the different oral care interventions between the two groups, the feeding and treatment strategies were the same, according to the protocol of the NICU. It was advisable to increase the milk volume not to exceed $20 \mathrm{ml} / \mathrm{kg}$.d. All infants were observed until their discharge. The data of the infants who were discharged against medical advice were not analyzed.

\section{Quality improvement policy}

On the day preterm infants (gestational age $\leq 32$ weeks) were admitted to our NICU, special personnel were assigned to provide promotional breastfeeding education to the parents, who were required to pass the training and demonstrate conformity before starting to collect and deliver breastmilk. The clinician checked and recorded the status of breastmilk delivery every day and provided feedback to the parents by telephone or WeChat (a mobile application offering instant messaging service), with repeated emphasis on the importance of breastfeeding in order to improve the rate of breastfeeding, which is important for OAC research to proceed smoothly in our NICU.

\section{Outcome assessment}

(1) The primary outcomes included the incidence of NEC ${ }^{[12]}$ (according to the modified Bell classification, Bell stage 2 or 3 ) and LOS ${ }^{[13]}$ (including clinical sepsis and proven sepsis). (2) Secondary outcomes included the age of achieving full enteral feeding $(160 \mathrm{ml} / \mathrm{kg} . \mathrm{d})$, full oral feeding, rate of weight gain ( $\mathrm{g} / \mathrm{kg} . \mathrm{d})$, days of mechanical ventilation and noninvasive ventilation, indwelling time of a peripherally inserted central catheter (PICC), length of hospitalization, etc. Related complications included patent ductus arteriosus $^{[14]}(\mathrm{PDA})$, severe intraventricular hemorrhage (IVH) ${ }^{[15]}$ (diagnosis and classification by ultrasound, stage 3 or 4 ), bronchopulmonary dysplasia ${ }^{[16]}$ (BPD, oxygen $>30 \%$ at 36 weeks corrected gestation), periventricular leukomalacia ${ }^{[17]}(\mathrm{PVL})$, retinopathy of prematurity ${ }^{[18]}(\mathrm{ROP})$ and cholestasis. (3) Apnea, bradycardia (defined as heart rate $<90$ beats/min), tachycardia (defined as heart rate $>180$ beats/min), desaturation (defined as a low saturation below $88 \%$ ) and oral mucous membrane injury as possible side effects.

\section{Sample size calculation}

There are few published trials that have reported a decline in the incidence of NEC or LOS with OAC in preterm infants ( $G A \leq 32$ weeks); thus, it was difficult to calculate the required sample size. One approach was to calculate the sample size (250 preterm infants were targeted) based on our records of a 10 12\% incidence for NEC and a 13 15\% incidence for LOS among preterm infants (GA $\leq 32$ weeks) in our NICU. 
Alternatively, in-hospital data were analyzed among infants with $\mathrm{GA} \leq 32$ weeks admitted over the past decade. After the statistical analysis of data, expected infant births during the research period meeting the inclusion criteria were calculated, and $100 \sim 150$ neonates in each group of the study were planned for enrollment.

\section{Statistical analysis}

Statistical analysis was performed using SPSS statistical software (SPSS for IBM. Version 23.0.0). The results are presented as the mean \pm standard deviation, median (interquartile range), or number (percentage) unless otherwise stated. Kolmogorov-Smirnov's and Levene's tests were used to check the normality and homogeneity of variance for measurement data, respectively. Student's t test was used to compare continuous parametric variables, the Mann-Whitney $\mathrm{U}$ test was used for continuous nonparametric variables, the $\chi 2$ test or Fisher's exact test was used for categorical variables, and the multiple independent samples Kruskal-Wallis $\mathrm{H}$ test was used for one-way and orderly variables when appropriate. A p-value of less than 0.05 was considered statistically significant.

\section{Results}

The flow of participants through stages of the trial is shown in Fig. 1. There were a total of 271 premature infants meeting the inclusion criteria, and 11 cases were excluded (including 5 cases of breastfeeding contraindications in the mothers, 1 case of Pierre-Robin syndrome, 1 case of congenital chromosomal abnormality, 1 case of congenital intestinal atresia, 3 cases of congenital cytomegalovirus infection), and 8 infants were discharged against medical advice ( 5 infants in the control group and 3 infants in the intervention group). Three infants in the control group and 3 infants in the OAC group died within 24 hours after discharge, and 2 infants in the control group died $3 \sim 5$ days after discharge; none of these infants died of NEC or LOS. A total of 252 cases were finally included: 125 cases in the control group and 127 cases in the OAC group; none of these infants died of NEC or LOS, and all of them were discharged in a healthy condition.

Maternal and neonatal general characteristics are shown in Table 1. There were no statistically significant differences in the patient demographics or baseline characteristics $(P>0.05)$. No cases of oral mucous membrane injury were observed in either group. For all infants in this study, oxygen saturation measures remained stable or decreased slightly during the intervention. There were no episodes of apnea, bradycardia or tachycardia. 
Table 1

Patient Demographics and Baseline Characteristics

\begin{tabular}{|c|c|c|c|c|}
\hline Patient Demographics & $\begin{array}{l}\text { OAC Group }(n= \\
127)\end{array}$ & $\begin{array}{l}\text { Control } \\
\text { Group } \\
(n=125)\end{array}$ & $t / x^{2}$-value & $P$-value \\
\hline Gender (male), n (\%) & $65(51.2)$ & $78(62.4)$ & 3.230 & 0.072 \\
\hline Gestational age (weeks), mean \pm SD & $30.0 \pm 1.8$ & $29.7 \pm 2.0$ & 1.451 & 0.148 \\
\hline Birth weight(g), mean \pm SD & $\begin{array}{l}1,302.3 \pm \\
209.8\end{array}$ & $\begin{array}{l}1,328.7 \pm \\
222.2\end{array}$ & 0.972 & 0.332 \\
\hline Small for gestational age, $\mathrm{n}(\%)$ & 22(17.3) & 18(14.4) & 0.403 & 0.526 \\
\hline Extremely low birth weight infant, n (\%) & $14(11.0)$ & $11(8.8)$ & 0.349 & 0.555 \\
\hline Sicker infants, n (\%) & $20(15.7)$ & $22(17.6)$ & 0.156 & 0.693 \\
\hline Birth head circumference $(\mathrm{cm})$, mean \pm SD & $27.2 \pm 1.5$ & $27.1 \pm 1.8$ & 0.419 & 0.675 \\
\hline Apgar score at 5 min, median (IQR) & $9(9 \sim 10)$ & $9(9 \sim 10)$ & $\begin{array}{l}7 \\
646.000\end{array}$ & 0.402 \\
\hline TRIPS score, median (IQR) & $13(8 \sim 13)$ & $13(8 \sim 13)$ & $\begin{array}{l}8, \\
848.000\end{array}$ & 0.063 \\
\hline NRDS, n (\%) & $39(30.7)$ & $30(24.0)$ & 1.426 & 0.232 \\
\hline Pulmonary surfactant use, n (\%) & $37(29.1)$ & $30(24.0)$ & 0.851 & 0.356 \\
\hline Breast feeding, $\mathrm{n}(\%)$ & 108(85.0) & 103(82.4) & 0.322 & 0.570 \\
\hline Days of breast feeding $(\mathrm{d})$, mean \pm SD & $30.4 \pm 20.9$ & $29.9 \pm 18.0$ & 0.196 & 0.845 \\
\hline Time to start OAC/NS (h), mean \pm SD & $24.5 \pm 11.2$ & $23.8 \pm 10.9$ & 0.501 & 0.617 \\
\hline $\begin{array}{l}\text { Established enteral feeding within } 24 \text { hours } \\
\text { after birth, } n(\%)\end{array}$ & $111(87.4)$ & 105(84.0) & 0.595 & 0.440 \\
\hline Maternal age $(y)$, mean $\pm S D$ & $31.8 \pm 4.5$ & $31.8 \pm 4.8$ & 0.026 & 0.980 \\
\hline Gestational hypertension, n (\%) & 23(18.1) & $15(12.0)$ & 1.837 & 0.175 \\
\hline Gestational diabetes mellitus, n (\%) & $42(33.1)$ & $34(27.2)$ & 1.031 & 0.310 \\
\hline Antenatal steroid use, $\mathrm{n}(\%)$ & 115(90.6) & $115(92.0)$ & 0.166 & 0.684 \\
\hline Antenatal magnesium sulfate use, $\mathrm{n}(\%)$ & $82(64.6)$ & $68(54.4)$ & 2.703 & 0.100 \\
\hline Twin or multiple gestation, $\mathrm{n}(\%)$ & 48(37.8) & $42(33.6)$ & 0.483 & 0.487 \\
\hline
\end{tabular}

TRIPS: transport risk index of physiologic stability. NRDS: neonatal respiratory distress syndrome. OAC: oropharyngeal administration of colostrum. IQR: interquartile range. SD: standard deviation. Sicker infants were defined as infants whose mechanical ventilation was started within the first 3 postnatal days and continued through at least 3 days or until death. 


\begin{tabular}{|c|c|c|c|c|}
\hline Patient Demographics & $\begin{array}{l}\text { OAC Group }(n= \\
127)\end{array}$ & $\begin{array}{l}\text { Control } \\
\text { Group } \\
(n=125)\end{array}$ & $t / x^{2}$ value & $P$ value \\
\hline Cesarean delivery, $\mathrm{n}(\%)$ & $71(56.8)$ & $77(60.6)$ & 0.381 & 0.537 \\
\hline Premature rupture of membranes, $\mathrm{n}(\%)$ & $50(39.4)$ & $60(48.0)$ & 1.907 & 0.167 \\
\hline Histologic chorioamnionitis, n (\%) & 42(33.1) & $33(26.4)$ & 1.341 & 0.247 \\
\hline \multicolumn{5}{|c|}{$\begin{array}{l}\text { TRIPS: transport risk index of physiologic stability. NRDS: neonatal respiratory distress syndrome. } \\
\text { OAC: oropharyngeal administration of colostrum. IQR: interquartile range. SD: standard deviation. } \\
\text { Sicker infants were defined as infants whose mechanical ventilation was started within the first } 3 \\
\text { postnatal days and continued through at least } 3 \text { days or until death. }\end{array}$} \\
\hline
\end{tabular}

A comparison of the incidence of NEC and LOS between the two groups is shown in Table 2. There were 13 cases of NEC (Bell stage 2 or 3 ) in the control group (10.4\%), including 4 cases of stage $2 A, 6$ cases of stage $2 B, 2$ cases of stage $3 A$, and 1 case of stage $3 B$. All 3 infants with stage 3 underwent surgery. There were 3 cases of NEC (Bell stage 2 or 3 ) in the OAC group (2.4\%), all of whom were stage $2 A$ and recovered without surgery. The incidence of NEC (Bell stage 2 or 3 ) was lower in the OAC group than in the control group $\left[3 / 127(2.4 \%)\right.$ vs. $\left.13 / 125(10.4 \%), \chi^{2}=6.845 \otimes \square=0.009\right]$. There were 17 cases of LOS in the control group (13.6\%), including 6 cases of clinical sepsis and 11 cases of proven sepsis ( 3 cases of Candida haemulonii, 1 case of Enterobacter aerogenes, 1 case of Enterococcus faecium D group, 1 case of Enterococcus faecalis D group, 1 case of Escherichia coli, 2 cases of Klebsiella pneumoniae, 2 cases of Enterobacter cloacae). There were 6 cases of LOS in the OAC group (4.7\%), including 3 cases of clinical sepsis and 3 cases of proven sepsis ( 1 case of Klebsiella pneumoniae, 1 case of Staphylococcus bred, 1 case of Candida haemulonii). The incidences of LOS and proven LOS were lower in the OAC group than in the control group [LOS: $6 / 127(4.7 \%)$ vs. $17 / 125 \rrbracket 13.6 \% \bigotimes \bigotimes \chi 2=5.983 \square \square=0.014$;proven LOS: $3 / 127 \rrbracket 2.4 \% \bigotimes V$ s. $\left.11 / 125 \rrbracket 8.8 \% \bigotimes \bigotimes \chi^{2}=4.976 \rrbracket \square=0.026\right]$ (in Fig. 2). 
Table 2

Clinical Outcomes Between the Two Groups at the Time of Discharge

\begin{tabular}{|c|c|c|c|c|}
\hline Clinical Outcomes & $\begin{array}{l}\text { OAC } \\
\text { Group } \\
(n=127)\end{array}$ & $\begin{array}{l}\text { Control Group } \\
(n=125)\end{array}$ & $x^{2}$-value & $\begin{array}{l}\mathrm{P} \text { - } \\
\text { value }\end{array}$ \\
\hline NEC(Bell stage 2 or 3 ), n (\%) & $3(2.4)$ & 13(10.4) & 6.845 & 0.009 \\
\hline Bell stage $2, \mathrm{n}(\%)$ & $3(2.4)$ & $10(8.0)$ & 4.093 & 0.043 \\
\hline Bell stage $3, \mathrm{n}(\%)$ & $0(0.0)$ & $3(2.4)$ & -a & 0.121 \\
\hline LOS, n (\%) & $6(4.7)$ & 17(13.6) & 5.983 & 0.014 \\
\hline Clinical sepsis, n (\%) & $3(2.4)$ & $6(4.8)$ & -a & 0.332 \\
\hline Proven sepsis, n (\%) & $3(2.4)$ & $11(8.8)$ & 4.976 & 0.026 \\
\hline Patent ductus arteriosus, n (\%) & $45(35.4)$ & $33(26.4)$ & 2.405 & 0.121 \\
\hline $\begin{array}{l}\text { Intraventricular hemorrhage (grade } 3 \text { or } \\
4), n(\%)\end{array}$ & $2(1.6)$ & $9(7.2)$ & 4.775 & 0.029 \\
\hline Periventricular leukomalacia, n (\%) & $0(0.0)$ & $1(0.8)$ & -a & 0.496 \\
\hline Bronchopulmonary dysplasia, n (\%) & $7(5.5)$ & $10(8.0)$ & 0.620 & 0.431 \\
\hline Retinopathy of prematurity, $\mathrm{n}(\%)$ & 18(14.6) & 16(13.4) & 0.071 & 0.790 \\
\hline Cholestasis, n (\%) & $3(2.4)$ & $9(7.2)$ & 3.251 & 0.071 \\
\hline $\begin{array}{l}\text { Age of achieving full enteral feeding (d), } \\
\text { median (IQR) }\end{array}$ & $22.0(16.0 \sim 29.0)$ & $25.0(18.0 \sim 39.0)$ & $\begin{array}{l}6 \\
424.500\end{array}$ & 0.009 \\
\hline $\begin{array}{l}\text { Age of achieving full oral feeding }(\mathrm{d}) \\
\text { mean } \pm \text { SD }\end{array}$ & $34.1 \pm 16.3$ & $35.0 \pm 17.5$ & 0.418 & 0.676 \\
\hline Rate of weight gain $(\mathrm{kg} . \mathrm{d})$, mean \pm SD & $13.5 \pm 3.8$ & $13.2 \pm 3.4$ & 0.579 & 0.563 \\
\hline Indwelling time of PICC $(d)$, mean \pm SD & $24.7 \pm 11.4$ & $24.9 \pm 13.2$ & 0.120 & 0.905 \\
\hline $\begin{array}{l}\text { Days of mechanical ventilation (d), } \\
\text { median (IQR) }\end{array}$ & $4.3(2.0 \sim 11.0)$ & $5.1(3.2 \sim 9.7)$ & 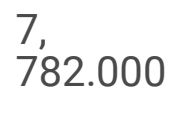 & 0.679 \\
\hline $\begin{array}{l}\text { Days of noninvasive ventilation (d), } \\
\text { median (IQR) }\end{array}$ & $9.0(4.0 \sim 25.0)$ & $9.0(4.0 \sim 18.0)$ & $\begin{array}{l}8, \\
278.000\end{array}$ & 0.556 \\
\hline Length of hospitalization (d), mean \pm SD & $41.1 \pm 16.3$ & $43.1 \pm 17.1$ & 0.957 & 0.339 \\
\hline
\end{tabular}


A comparison of secondary outcomes between the two groups is shown in Table 2. The incidence of IVH (stage 3 or 4 ) was lower in the OAC group than in the control group $\left[2 / 127(1.6 \%)\right.$ vs. $9 / 125(7.2 \%), \chi^{2}=$ 4.775 $\triangle \square=0.029$ ]. In addition, the age was significantly shorter in terms of achieving full enteral feeding in

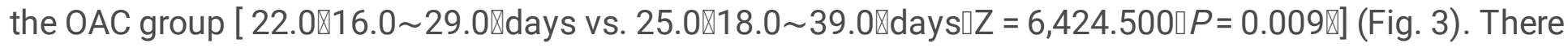
were no statistically significant differences between the two groups in the incidences of PDA, BPD, PVL, ROP, cholestasis (in Fig. 2) or other secondary outcomes $(P>0.05)$.

A comparison of the ELBW infants in the two groups is shown in Table 3. Twenty-five cases were finally included: 11 cases in the control group and 14 cases in the OAC group. One case of NEC with stage $3 A$ in the control group (9.1\%), and this infant underwent surgery. In the OAC group, 1 case of NEC with stage $2 \mathrm{~A}$ occurred $(7.1 \%)$ and did not necessitate surgery. The incidence of NEC (Bell stage 2 or 3 ) among the ELBW infants in the OAC group was not significantly different from that in the control group $(P=1.000)$. There were 4 cases of LOS in the control group (36.4\%), including 1 case of clinical sepsis and 3 cases of proven sepsis (1 case of Candida haemulonii, 1 case of Enterobacter cloacae, 1 case of Klebsiella pneumoniae), while no LOS cases occurred in the intervention group. The incidence of LOS among ELBW infants was lower in the OAC group than in the control group [0/14 (0.0\%) vs. 4/11(36.4\%), $P=0.026$. The incidence of IVH (stage 3 or 4 ) and the age of achieving full enteral feeding for the ELBW infants were lower and shorter in the intervention group than in the control group $[1 / 14(7.1 \%)$ vs. $6 / 11(54.5 \%) \square P=$ $0.021 ; 34.1 \pm 8.1$ days vs. $48.5 \pm 22.0$ days $\square \mathrm{t}=2.282, P=0.032]$ (Fig. 3 ). There were no statistically significant differences between the two groups in other secondary outcomes. 
Table 3

Clinical Outcomes Between the Two Groups of Extremely Low Birth Weight Infants at the Time of Discharge

\begin{tabular}{|c|c|c|c|c|}
\hline Clinical Outcomes & $\begin{array}{l}\text { OAC Group }(n= \\
\text { 14) }\end{array}$ & $\begin{array}{l}\text { Control Group } \\
(n=11)\end{array}$ & $\begin{array}{l}x^{2}- \\
\text { value }\end{array}$ & $\begin{array}{l}\mathrm{P}- \\
\text { value }\end{array}$ \\
\hline NEC(Bell stage 2 or 3$), \mathrm{n}(\%)$ & $1(7.1)$ & $1(9.1)$ & $-a$ & 1.000 \\
\hline Bell stage $2, \mathrm{n}(\%)$ & $1(7.1)$ & $0(0.0)$ & $\_a$ & 1.000 \\
\hline Bell stage $3, \mathrm{n}(\%)$ & $0(0.0)$ & $1(9.1)$ & $-a$ & 0.440 \\
\hline LOS, n (\%) & $0(0.0)$ & $4(36.4)$ & $-a$ & 0.026 \\
\hline Clinical sepsis, n (\%) & $0(0.0)$ & $1(9.1)$ & $-a$ & 0.440 \\
\hline Proven sepsis, n (\%) & $0(0.0)$ & $3(27.3)$ & $\_a$ & 0.072 \\
\hline Patent ductus arteriosus, n (\%) & $6(42.9)$ & $8(72.7)$ & $-a$ & 0.227 \\
\hline $\begin{array}{l}\text { Intraventricular hemorrhage (grade } 3 \text { or } 4 \text { ), } \\
\text { n (\%) }\end{array}$ & $1(7.1)$ & $6(54.5)$ & -a & 0.021 \\
\hline Periventricular leukomalacia, n (\%) & $0(0.0)$ & $0(0.0)$ & ${ }_{-}^{a}$ & - \\
\hline Bronchopulmonary dysplasia, n (\%) & $3(21.4)$ & $3(27.3)$ & $-a$ & 1.000 \\
\hline Retinopathy of prematurity, $\mathrm{n}(\%)$ & $7(50.0)$ & $4(36.4)$ & $-a$ & 0.689 \\
\hline Cholestasis, n (\%) & $1(7.1)$ & $3(27.3)$ & $-a$ & 0.288 \\
\hline $\begin{array}{l}\text { Age of achieving full enteral feeding (d), } \\
\text { mean } \pm S D\end{array}$ & $34.1 \pm 8.1$ & $48.5 \pm 22.0$ & 2.282 & 0.032 \\
\hline $\begin{array}{l}\text { Age of achieving full oral feeding (d), mean } \\
\pm S D\end{array}$ & $61.1 \pm 15.1$ & $62.9 \pm 23.9$ & 0.235 & 0.816 \\
\hline Rate of weight gain $(\mathrm{kg} . \mathrm{d})$, mean \pm SD & $17.8 \pm 3.7$ & $16.4 \pm 3.1$ & 0.986 & 0.334 \\
\hline Indwelling time of PICC (d), mean \pm SD & $36.9 \pm 11.5$ & $40.5 \pm 14.6$ & 0.693 & 0.495 \\
\hline $\begin{array}{l}\text { Days of mechanical ventilation }(\mathrm{d}) \text {, median } \\
\text { (IQR) }\end{array}$ & $15.0(4.0 \sim 50.0)$ & $13.0(4.0 \sim 13.0)$ & 81.000 & 0.851 \\
\hline $\begin{array}{l}\text { Days of noninvasive ventilation }(\mathrm{d}) \text {, mean } \pm \\
\text { SD }\end{array}$ & $38.7 \pm 17.9$ & $32.0 \pm 15.7$ & 0.982 & 0.336 \\
\hline Length of hospitalization, mean \pm SD & $71.0 \pm 17.4$ & $74.6 \pm 20.6$ & 0.479 & 0.636 \\
\hline
\end{tabular}


A comparison of the sicker infants in the two groups is shown in Table 4. Forty-two cases were finally included: 22 cases in the control group and 20 cases in the OAC group. The difference in distribution among sicker infants in both groups was not significant. The incidence of NEC (Bell stage 2 or 3 ) among the sicker infants was lower in the OAC group than in the control group $[1 / 20(5.0 \%)$ vs. 9/22 $(40.9 \%), \square=0.010]$. The incidence of LOS among the sicker infants in the OAC group was not significantly

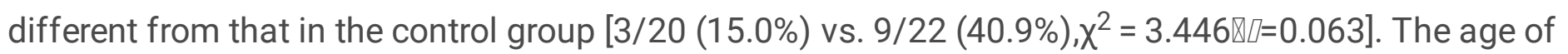
achieving full enteral feeding for the sickest infants was shorter in the OAC group than in the control

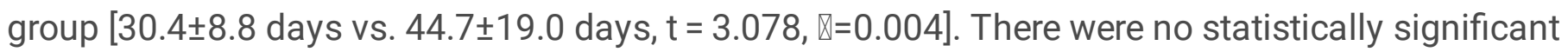
differences between the two groups in other secondary outcomes. 
Table 4

Clinical Outcomes Between the Two Groups of Sicker Infants at the Time of Discharge

\begin{tabular}{|c|c|c|c|c|}
\hline Clinical Outcomes & $\begin{array}{l}\text { OAC Group }(n= \\
20)\end{array}$ & $\begin{array}{l}\text { Control } \\
\text { Group } \\
(n=22)\end{array}$ & $\begin{array}{l}x^{2}- \\
\text { value - }\end{array}$ & $\begin{array}{l}\mathrm{P}- \\
\text { value }\end{array}$ \\
\hline NEC(Bell stage 2 or 3 ), n (\%) & $1(5.0)$ & $9(40.9)$ & $-a$ & 0.010 \\
\hline Bell stage $2, \mathrm{n}(\%)$ & $1(5.0)$ & $6(27.3)$ & _a & 0.096 \\
\hline Bell stage $3, \mathrm{n}(\%)$ & $0(0.0)$ & $3(13.6)$ & $-a$ & 0.233 \\
\hline LOS, n (\%) & $3(15.0)$ & $9(40.9)$ & 3.446 & 0.063 \\
\hline Clinical sepsis, n (\%) & $2(10.0)$ & $3(13.6)$ & $-a$ & 1.000 \\
\hline Proven sepsis, n (\%) & $1(5.0)$ & $6(27.3)$ & $-a$ & 0.096 \\
\hline Patent ductus arteriosus, $\mathrm{n}(\%)$ & $11(55.0)$ & $11(50.0)$ & 0.105 & 0.746 \\
\hline $\begin{array}{l}\text { Intraventricular hemorrhage (grade } 3 \text { or } 4 \text { ), } n \\
(\%)\end{array}$ & $1(5.0)$ & $4(18.2)$ & $-a$ & 0.346 \\
\hline Periventricular leukomalacia, n (\%) & $0(0.0)$ & $0(0.0)$ & $-a$ & - \\
\hline Bronchopulmonary dysplasia, n (\%) & $4(20.0)$ & $8(36.4)$ & 1.375 & 0.241 \\
\hline Retinopathy of prematurity, $\mathrm{n}$ (\%) & $4(20.0)$ & $5(22.7)$ & $-a$ & 1.000 \\
\hline Cholestasis, n (\%) & $0(0.0)$ & $4(18.2)$ & $-a$ & 0.109 \\
\hline $\begin{array}{l}\text { Age of achieving full enteral feeding (d), } \\
\text { Mean } \pm \text { SD }\end{array}$ & $30.4 \pm 8.8$ & $44.7 \pm 19.0$ & 3.078 & 0.004 \\
\hline $\begin{array}{l}\text { Age of achieving full oral feeding (d), Mean } \pm \\
\text { SD }\end{array}$ & $52.7 \pm 21.6$ & $55.9 \pm 20.3$ & 0.504 & 0.617 \\
\hline Rate of weight gain (kg.d), mean \pm SD & $16.3 \pm 3.8$ & $14.5 \pm 3.3$ & 1.626 & 0.112 \\
\hline $\begin{array}{l}\text { Days of mechanical ventilation }(d) \text {, mean } \pm \\
\text { SD }\end{array}$ & $6.5 \pm 4.9$ & $11.0 \pm 20.1$ & 0.985 & 0.331 \\
\hline $\begin{array}{l}\text { Days of noninvasive ventilation }(d) \text {, mean } \pm \\
\text { SD }\end{array}$ & $31.5 \pm 18.9$ & $28.5 \pm 15.8$ & 0.560 & 0.579 \\
\hline Indwelling time of PICC (d), mean \pm SD & $30.6 \pm 16.0$ & $30.7 \pm 14.4$ & 0.017 & 0.986 \\
\hline Length of hospitalization, mean \pm SD & $60.5 \pm 23.0$ & $62.3 \pm 19.5$ & 0.270 & 0.789 \\
\hline
\end{tabular}




\section{Discussion}

\section{OAC procedures}

In the published literature, the application time of OAC could last for 5 days after birth until longer, even extending until the baby can receive partial oral feeding or reaches the correct gestational age at 32 weeks ${ }^{[19]}$. Colostrum is defined as breast milk produced within $5 \sim 7$ days after delivery; it is rich in immunologic cellular activity factors and growth factors, whose concentration is higher until 14 20 days after birth, especially in breastmilk from mothers of premature infants ${ }^{[20,21][21]}$. Therefore, in theory, an OAC duration that extends as long as possible will bring more benefits to premature infants. Colostrum of the infants' own mothers was selected in our study, and setting the OAC period at 10 days provided the preterm infants more benefits without unduly burdening the nurse.

There were many variations in the colostrum dosage, the duration of each administration, and the frequency of OAC in the published literature. The colostrum dosage ranges from $0.1 \mathrm{ml}$ to $1.0 \mathrm{ml}$. Some studies have proposed that the duration of each administration should be less than 5 seconds on one side of the buccal mucosa to reduce friction and irritation to vulnerable mucosal tissues; most articles have not mention this administration specifically, and the reported frequency varies from once every 2 hours to once every 6 hours $^{[19]}$. In our study, a colostrum volume of $0.4 \mathrm{ml}$ was the average used in the previously published studies, and the 2 min duration of each administration was based on the experience of nurses in our NICU.

Moreover, our study used sterile silicone fingerstalls to smear the mouth, aiming to reduce the possible absorption of active substances in breastmilk by cotton swabs; we also used disposable clean and sealed milk storage cups for breastmilk collection in order to reduce secondary pollution during transfer.

\section{The safety of OAC}

There were no adverse events, including oral mucosal damage, apnea, bradycardia, tachycardia and desaturation, in our study, even in the ELBW and sicker infants who needed mechanical ventilation started within the first 3 postnatal days and continued through at least 3 days. Therefore, OAC may be considered a safe procedure in the NICU for preterm infants.

\section{OAC in preventing NEC}

NEC is a common complication in preterm infants that leads to many adverse consequences, which can increase the incidence of mortality and morbidity ${ }^{[22]}$. OAC is recognized as a new precaution against $N E C^{[11,23]}$. Biological studies have shown that OAC affects the prevention of NEC through the following mechanisms: (a) The cytokines in breastmilk interact with the oropharyngeal lymphoid tissue system, which causes $T$ cell activation and leads to immune activation and anti-inflammatory reactions of various terminal organs. (b) Many protective biological factors in breastmilk are absorbed by the oral mucosa and then into the gastrointestinal tract to play a role in promoting maturation, anti-inflammation and barrier protection. (c) The antioxidants in breastmilk (such as peroxides, superoxide dismutase, etc.) 
can directly protect the immune cells in the oropharynx and can reach the intestinal tract to protect the mucosal barrier from oxidative damage, preventing oxidative stress-induced intestinal flora changes and translocation ${ }^{[24-27]}$. Although biological theory supports the results of these studies, most clinical studies and meta-analyses published in recent years have indicated that OAC cannot reduce the incidence of NEC ${ }^{[28-31]}$.

Our results showed that the incidence of NEC in the OAC group was significantly lower for preterm infants with $\mathrm{GA} \leq 32$ weeks (10.4 2.4\%), and the advantage seemed more obvious in sicker infants (40.9 $5.0 \%$ ); no surgery was required among the NEC (stage 3 ) cases in the OAC group. These results are consistent with a previous study on the standard feeding protocol in preterm infants by McCallie and his team. That study enrolled 147 premature infants with $B W \leq 1500 \mathrm{~g}$ and indicated that the incidence of NEC was significantly decreased among infants with minimal oral feeding (VLBW: 18.1\% 3.1\%, ELBW: $35.5 \% \sim 7.7 \%)^{[32]}$. Similar to our study findings, a larger colostrum dosage, longer duration and higher frequency of OAC may be the reasons for the decrease in NEC. However, there was no difference in the incidence of NEC among ELBW infants in our study, which may be related to the insufficient sample size. Thus, OAC may have a potential advantage in decreasing the incidence of NEC, but this is not certain.

\section{OAC in preventing LOS}

LOS is a multifactorial disease. Delayed feeding, artificial feeding and antibiotics lead to mucosal colonization of pathogenic bacteria, and the mucosal barrier of preterm infants is weak; thus, various invasive operations may cause colonized pathogenic bacteria to cross the immature epithelial barrier and then enter the blood, ultimately causing infection ${ }^{[33]}$. Mother's milk, particularly colostrum, is rich in cytokines and other immune agents that provide bacteriostatic, bactericidal, antiviral, anti-inflammatory, and immunomodulatory protective agents against infection by $O A C^{[23][34]}$. Our study showed that the incidence of LOS was lower in the OAC group among preterm infants with GA $\leq 32$ weeks $(13.6 \% \sim 4.7 \%)$ and ELBW (36.4\% 0.0\%). Furthermore, the LOS reduction may be associated with a lower age of achieving full enteral feeding in our study.

An RCT by Lee, including 48 premature infants with $\mathrm{GA} \leq 28$ weeks, showed that OAC significantly reduced the incidence of clinical sepsis ${ }^{[35]}$. In Elgawad's study, OAC did not significantly reduce the incidence of proven sepsis, and the count of intraoral Klebsiella pneumoniae in the OAC intervention group showed a significant downward trend ${ }^{[36]}$. With further analysis of the types of pathogenic bacteria detected in proven sepsis cases, we also found that the incidence of fungal infection in the OAC group showed a significant downward trend, which may be related to protective biological factors such as lactoferrin in breastmilk, which can reduce the occurrence of invasive fungal infections through the inhibition of fungal colonization and overgrowth ${ }^{[37]}$. However, considering the variety of colonizing bacteria and conditional pathogens in different NICUs, the inhibitory effect of OAC on different pathogens needs to be further discussed.

\section{The role of OAC in preventing other complications}


IVH is an important cause of brain injury in premature infants. It was observed that the incidence of severe IVH decreased significantly in the OAC group, which was considered related to a possible mechanism in which the infection rate decreased after the application of OAC. Then, the incidence of infection-caused hypoxia/acidosis also decreased, which finally resulted in a brain-protection effect.

Many studies have shown that OAC may also have the advantages of lowering the age of achieving full enteral feeding and full oral feeding, reducing the incidence of feeding intolerance ${ }^{[29,30,34,36]}$, increasing the body weight at the correct gestational age of 36 weeks $^{[38]}$, reducing the length of hospital stay ${ }^{[29,31}$, ${ }^{39]}$, and prolonging the days of breastfeeding ${ }^{[40]}$. In our study, it was also observed that the age of achieving full enteral feeding was lower in the OAC group, which is of great significance for the management of premature infants. The possible mechanism might be that OAC stimulates oropharyngeal receptors, which improve the motility and secretory and absorptive abilities of the gastrointestinal tract.

\section{Limitations}

We acknowledge the limitations of conducting a single-center, nonblind trial. The sample size was relatively small, especially with respect to ELBW infants, so there may be deviations in the results. Second, there was a lack of assessment of long-term outcomes. Thus, large, multicenter, well-designed trials are required to more precisely and reliably evaluate the effects of OAC on short-term and long-term outcomes in preterm infants. Biological research should also be performed to address the immune effects in recipient infants.

\section{Conclusions}

This study strengthens the notion that OAC is a simple, safe procedure with potential advantages in decreasing the incidence of NEC, LOS, and severe IVH and facilitating a faster achievement of full enteral feeding in preterm infants with gestational age $\leq 32$ weeks. Therefore, OAC is worthy of being promoted and applied in preterm infants who are unable to feed by mouth during the first days of life.

\section{Abbreviations}

Oropharyngeal administration of colostrum (OAC)

necrotizing enterocolitis (NEC)

late-onset sepsis (LOS)

gestational age (GA)

birth weight(BW)

very low birth weight (VLBW) 
extremely low birth weight (ELBW)

neonatal intensive care unit (NICU)

incidence of intraventricular hemorrhage (IVH)

patent ductus arteriosus (PDA)

bronchopulmonary dysplasia (BPD)

periventricular leukomalacia (PVL)

retinopathy of prematurity $(\mathrm{ROP})$

\section{Declarations}

\section{Ethics approval and consent to participate}

The research was conducted in accordance with the Declaration of Helsinki, and the protocol was approved by the Ethics Committee of Fujian Provincial Maternity and Children's Hospital (No: 2017-502).

\section{Consent for publication}

We have the institutional consent form and send the form on submission.

\section{Availability of data and materials}

The datasets during and/or analyzed during the current study available from the corresponding author on reasonable request.

\section{Competing interests}

All the authors declare that there are no conflicts of interest.

\section{Funding}

This research was funded by the Social Developmental Induction Program of Fujian Province (No: 2018Y0006).

\section{Authors' contributions}

Xia OuYang and Wen-Long Xiu contributed to designing the study, performing the data analyses and drafting the manuscript. Chang-Yi Yang assisted in designing the study and revising the manuscript. YanHua Hu and Su-su Mei collected the clinical data. Qin Lin helped to manage the nursing procedures. All authors read and approved the final article. 


\section{Acknowledgements}

The authors express their sincere appreciation to the medical care personnel in the NICU at Fujian Provincial Maternity and Children's Hospital and thank the Fujian Provincial Department of Science and Technology for the funding support.

\section{References}

[1] Stoll BJ, Hansen NI, Bell EF, et al. Trends in Care Practices, Morbidity, and Mortality of Extremely Preterm Neonates, 1993-2012. JAMA. 2015. 314(10): 1039-51.

[2] Battersby C, Santhalingam T, Costeloe K, Modi N. Incidence of neonatal necrotising enterocolitis in high-income countries: a systematic review. Arch Dis Child Fetal Neonatal Ed. 2018. 103(2): F182-F189.

[3] Hodzic Z, Bolock AM, Good M. The Role of Mucosal Immunity in the Pathogenesis of Necrotizing Enterocolitis. Front Pediatr. 2017. 5: 40.

[4] Niño DF, Sodhi CP, Hackam DJ. Necrotizing enterocolitis: new insights into pathogenesis and mechanisms. Nat Rev Gastroenterol Hepatol. 2016. 13(10): 590-600.

[5] Stoll BJ, Hansen N, Fanaroff AA, et al. Late-onset sepsis in very low birth weight neonates: the experience of the NICHD Neonatal Research Network. Pediatrics. 2002. 110(2 Pt 1): 285-91.

[6] Polin RA, Denson S, Brady MT, Committee on Fetus and Newborn, Committee on Infectious Diseases. Epidemiology and diagnosis of health care-associated infections in the NICU. Pediatrics. 2012. 129(4): e1104-9.

[7] Munblit D, Abrol P, Sheth S, et al. Levels of Growth Factors and IgA in the Colostrum of Women from Burundi and Italy. Nutrients. 2018. 10(9).

[8] Le Doare K, Holder B, Bassett A, Pannaraj PS. Mother's Milk: A Purposeful Contribution to the Development of the Infant Microbiota and Immunity. Front Immunol. 2018. 9: 361.

[9] Lönnerdal B. Bioactive Proteins in Human Milk-Potential Benefits for Preterm Infants. Clin Perinatol. 2017. 44(1): 179-191.

[10] Maffei D, Schanler RJ. Human milk is the feeding strategy to prevent necrotizing enterocolitis. Semin Perinatol. 2017. 41(1): 36-40.

[11] Rodriguez NA, Meier PP, Groer MW, Zeller JM. Oropharyngeal administration of colostrum to extremely low birth weight infants: theoretical perspectives. J Perinatol. 2009. 29(1): 1-7.

[12] Bell MJ, Ternberg JL, Feigin RD, et al. Neonatal necrotizing enterocolitis. Therapeutic decisions based upon clinical staging. Ann Surg. 1978. 187(1): 1-7. 
[13] Dong Y, Speer CP. Late-onset neonatal sepsis: recent developments. Arch Dis Child Fetal Neonatal Ed. 2015. 100(3): F257-63.

[14] Huhta JC, Cohen M, Gutgesell HP. Patency of the ductus arteriosus in normal neonates: twodimensional echocardiography versus Doppler assessment. J Am Coll Cardiol. 1984. 4(3): 561-4.

[15] de Vries LS, Eken P, Dubowitz LM. The spectrum of leukomalacia using cranial ultrasound. Behav Brain Res. 1992. 49(1): 1-6.

[16] Voynow JA. "New" bronchopulmonary dysplasia and chronic lung disease. Paediatr Respir Rev. 2017. 24: 17-18.

[17] Agut T, Alarcon A, Cabañas F, et al. Preterm white matter injury: ultrasound diagnosis and classification. Pediatr Res. 2020. 87(Suppl 1): 37-49.

[18] Fierson WM, AMERICAN ACADEMY OF PEDIATRICS Section on Ophthalmology, AMERICAN ACADEMY OF OPHTHALMOLOGY, AMERICAN ASSOCIATION FOR PEDIATRIC OPHTHALMOLOGY AND STRABISMUS, AMERICAN ASSOCIATION OF CERTIFIED ORTHOPTISTS. Screening Examination of Premature Infants for Retinopathy of Prematurity. Pediatrics. 2018. 142(6).

[19] Rodriguez NA, Vento M, Claud EC, Wang CE, Caplan MS. Oropharyngeal administration of mother's colostrum, health outcomes of premature infants: study protocol for a randomized controlled trial. Trials. 2015. 16: 453.

[20] Furman L, Taylor G, Minich N, Hack M. The effect of maternal milk on neonatal morbidity of very lowbirth-weight infants. Arch Pediatr Adolesc Med. 2003. 157(1): 66-71.

[21] Walker A. Breast Milk as the Gold Standard for Protective Nutrients. J Pediatr. 2010. 156(2-supp-S): S3-S7.

[22] Frost Brandy L, Modi Biren P, Tom J, Caplan Michael S. New Medical and Surgical Insights Into Neonatal Necrotizing Enterocolitis: A Review. JAMA Pediatr. 2017. 171(1).

[23] Rodriguez NA, Caplan MS. Oropharyngeal administration of mother's milk to prevent necrotizing enterocolitis in extremely low-birth-weight infants: theoretical perspectives. J Perinat Neonatal Nurs. 2015. 29(1): 81-90.

[24] Garofalo NA, Caplan MS. Oropharyngeal Mother's Milk: State of the Science and Influence on Necrotizing Enterocolitis. Clin Perinatol. 2019. 46(1): 77-88.

[25] Gopalakrishna KP, Macadangdang BR, Rogers MB, et al. Maternal IgA protects against the development of necrotizing enterocolitis in preterm infants. Nat Med. 2019. 25(7): 1110-1115. 
[26] Hanson LA, Ahlstedt S, Andersson B, et al. Protective factors in milk and the development of the immune system. Pediatrics. 1985. 75(1 Pt 2): 172-6.

[27] Goldman AS, Chheda S, Keeney SE, Schmalstieg FC, Schanler RJ. Immunologic protection of the premature newborn by human milk. Semin Perinatol. 1994. 18(6): 495-501.

[28] Harshad P, Gayatri A, Sanjay P. Oropharyngeal Colostrum for Preterm Infants: A Systematic Review and Meta-Analysis. Advances in nutrition (Bethesda, Md.). 2019. 10(6).

[29] Tao J, Mao J, Yang J, Su Y. Effects of oropharyngeal administration of colostrum on the incidence of necrotizing enterocolitis, late-onset sepsis, and death in preterm infants: a meta-analysis of RCTs. Eur J Clin Nutr. 2020.

[30] Nasuf A, Ojha S, Dorling J. Oropharyngeal colostrum in preventing mortality and morbidity in preterm infants. Cochrane Database Syst Rev. 2018. 9: CD011921.

[31] Sharma D, Kaur A, Farahbakhsh N, Agarwal S. Role of Oropharyngeal Administration of Colostrum in Very-Low-Birth-Weight Infants for Reducing Necrotizing Enterocolitis: A Randomized Controlled Trial. Am J Perinatol. 2019 .

[32] McCallie KR, Lee HC, Mayer O, Cohen RS, Hintz SR, Rhine WD. Improved outcomes with a standardized feeding protocol for very low birth weight infants. J Perinatol. 2011. 31 Suppl 1: S61-7.

[33] Greenberg RG, Kandefer S, Do BT, et al. Late-onset Sepsis in Extremely Premature Infants: 2000-2011. Pediatr Infect Dis J. 2017. 36(8): 774-779.

[34] Martín-Álvarez E, Diaz-Castro J, Peña-Caballero M, et al. Oropharyngeal Colostrum Positively Modulates the Inflammatory Response in Preterm Neonates. Nutrients. 2020. 12(2).

[35] Lee J, Kim HS, Jung YH, et al. Oropharyngeal colostrum administration in extremely premature infants: an RCT. Pediatrics. 2015. 135(2): e357-66.

[36] Abd-Elgawad M, Eldegla H, Khashaba M, Nasef N. Oropharyngeal Administration of Mother's Milk Prior to Gavage Feeding in Preterm Infants: A Pilot Randomized Control Trial. JPEN J Parenter Enteral Nutr. 2020. 44(1): 92-104.

[37] Lausch KR, Schultz Dungu KH, Callesen MT, et al. Pediatric Candidemia Epidemiology and Morbidities: A Nationwide Cohort. Pediatr Infect Dis J. 2019. 38(5): 464-469.

[38] Seigel JK, Smith PB, Ashley PL, et al. Early administration of oropharyngeal colostrum to extremely low birth weight infants. Breastfeed Med. 2013. 8(6): 491-5.

[39] Garg B D, Balasubramanian H, Kabra N S, Bansal A. Effect of oropharyngeal colostrum therapy in the prevention of necrotising enterocolitis among very low birthweight neonates: A meta-analysis of 
randomised controlled trials. J Hum Nutr Diet. 2018. 31(5).

[40] Snyder R, Herdt A, Mejias-Cepeda N, Ladino J, Crowley K, Levy P. Early provision of oropharyngeal colostrum leads to sustained breast milk feedings in preterm infants. Pediatr Neonatol. 2017. 58(6): 534540 .

\section{Figures}

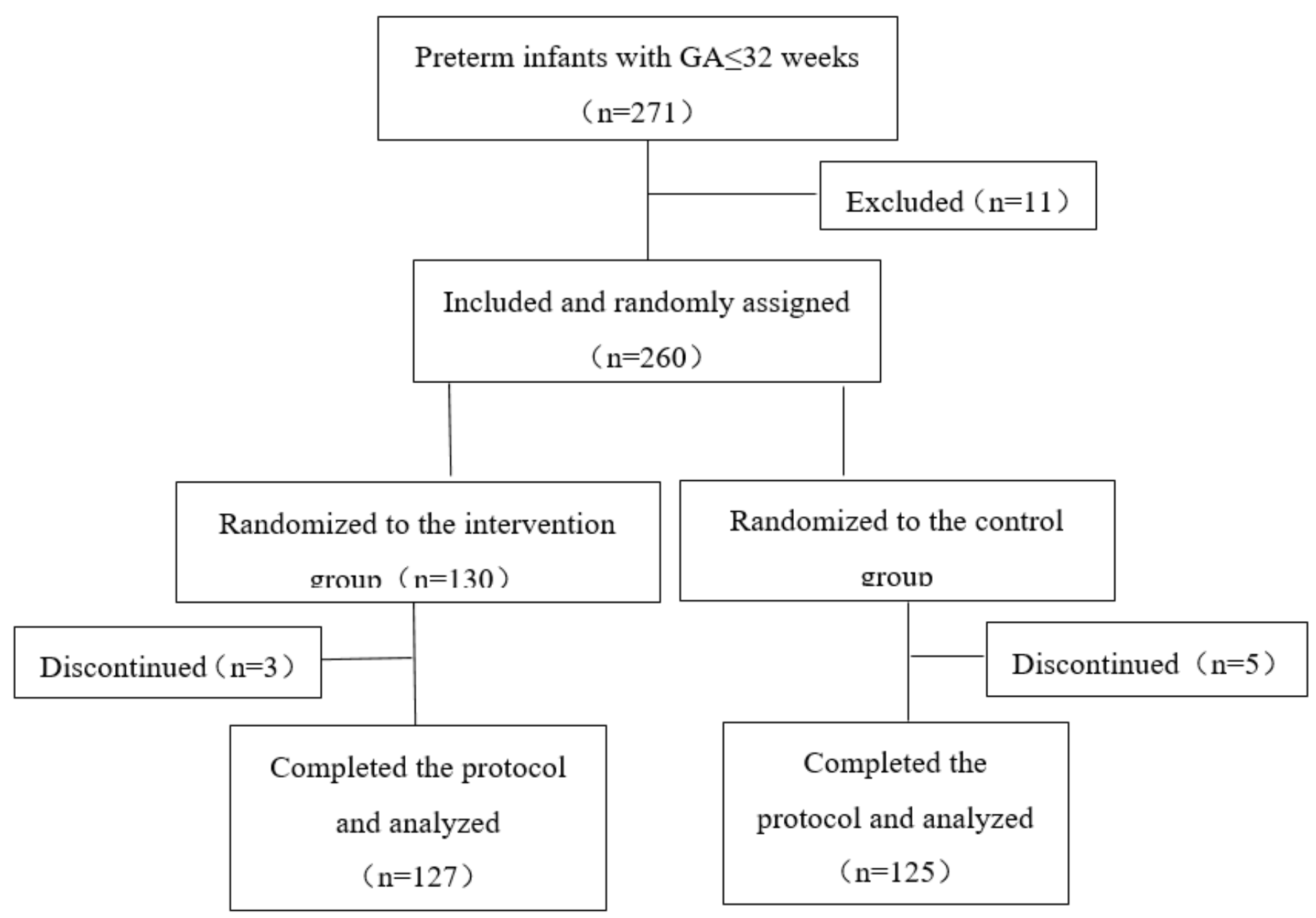

\section{Figure 1}

Flow Diagram of the Study Profile 


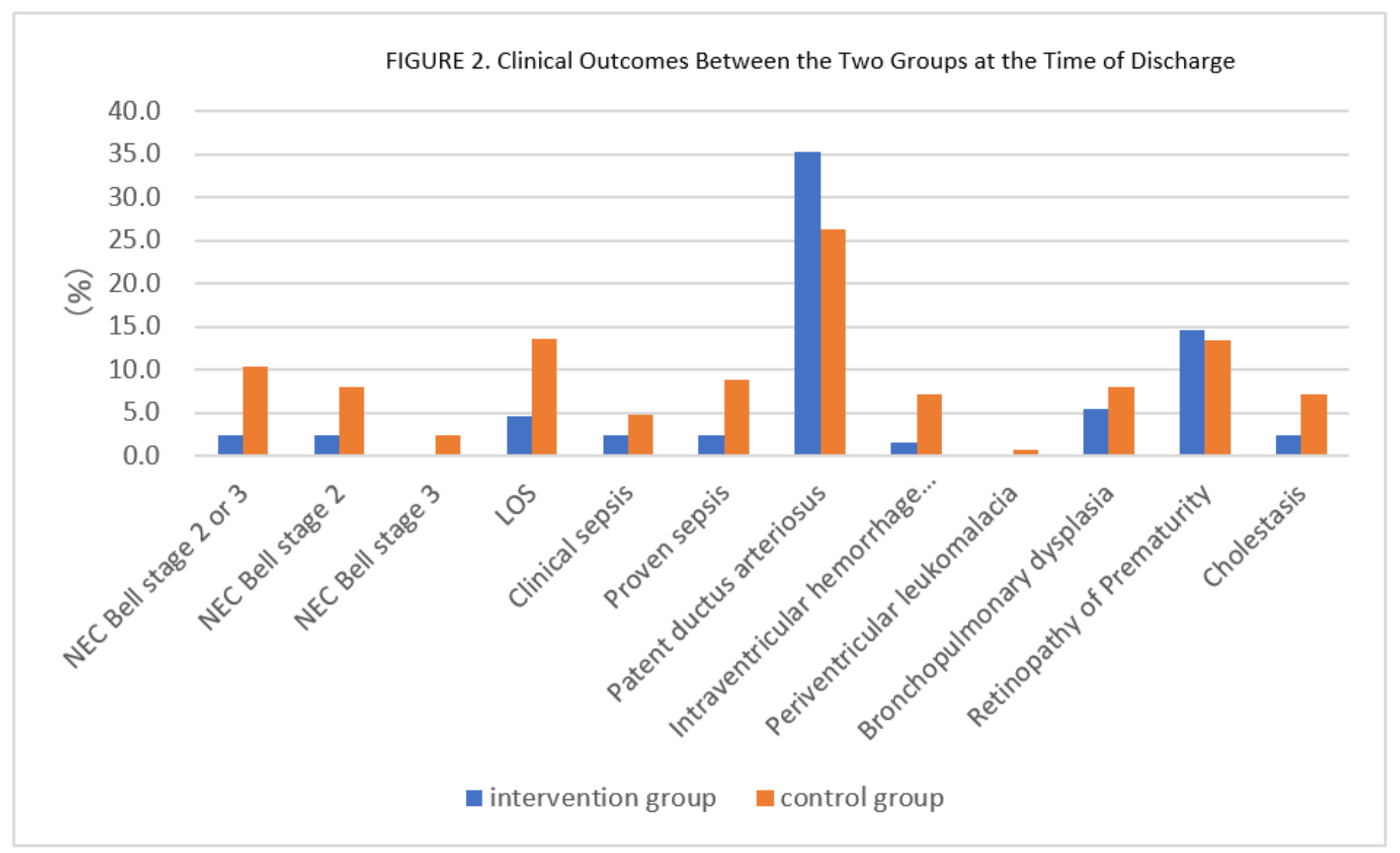

Figure 2

Clinical Outcomes Between the Two Groups at the Time of Discharge 

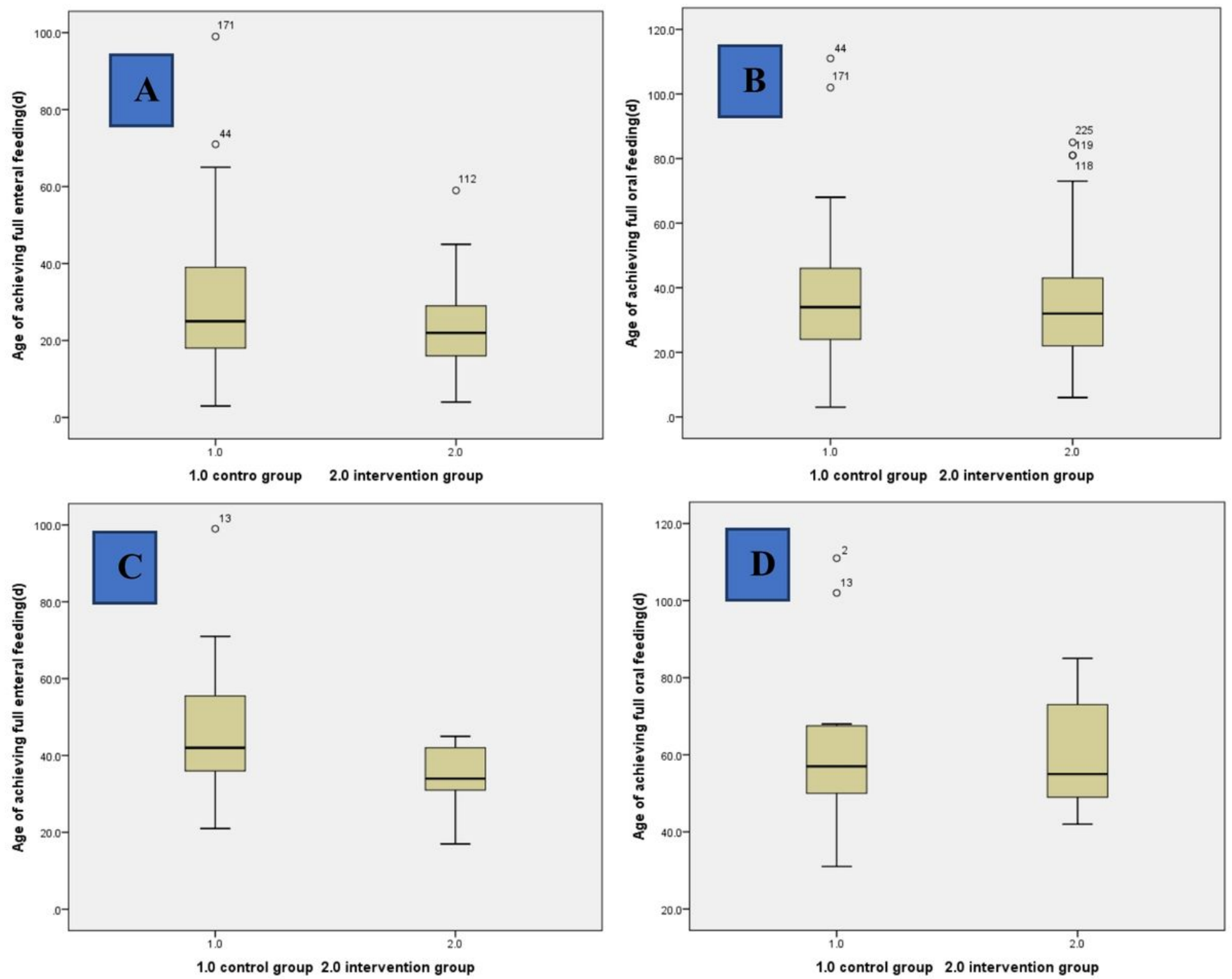

Figure 3

Box plots showing the significant effects of OAC, which shortened the time to achieve full enteral feeding in the intervention group (A) and ELBW preterm infants in the intervention group (C) but did not lower the age of achieving full oral feeding in the intervention group (B) or ELBW preterm infants in the intervention group (D). 